\title{
O papel da tradução e dos tradutores na produção de dicionários bilíngues no Brasil: uma história por contar
}

Adriana Ceschin Rieche*

\section{Introdução}

O presente artigo pretende investigar o papel da tradução e dos tradutores na produção de dicionários bilíngues especializados, com ênfase no par de idiomas inglês-português, a partir da segunda metade do século XX no Brasil. O objetivo é dar visibilidade aos tradutores autores dos dicionários selecionados para o estudo, mostrando, por meio da análise dos contextos em que essas obras foram produzidas, como elas são representativas de toda uma geração de tradutores e refletem o momento histórico em que se inserem. A estratégia de pesquisa será baseada na proposta de Anthony Pym, em seu Method in Translation History (2014), no qual o autor defende o "estudo humanístico dos tradutores humanos e suas ações sociais, tanto no bojo quanto além de suas traduções materiais" (PYM, 2014, p. 4).

Ciente do caráter muitíssimo abrangente da tarefa, o recorte está baseado no meu percurso profissional como tradutora especializada e usuária de dicionários bilíngues especializados, período que engloba os últimos 30 anos. A perspectiva do presente estudo será a de que os tradutores tiveram e têm participação relevante e ativa na produção de dicionários, sobretudo os bilíngues especializados. Utilizarei, como exemplo, alguns dicionários que me acompanham desde os tempos de estudante e outros

\footnotetext{
* Programa de Pós-Graduação em Estudos da Linguagem, Pontifícia Universidade Católica do Rio de Janeiro (PUC-Rio).
} 
adquiridos em função da necessidade de especialização. Acredito que algumas lições tiradas por meio dessa abordagem podem ajudar a especular sobre como será esta participação no futuro.

Dicionários sempre foram companheiros inseparáveis dos tradutores. Evidentemente, por sua própria natureza, a tarefa tradutória representa desafios, e a situação se complica quando a tradução envolve áreas especializadas. Em cada fase da tradução, as necessidades mudam e nem sempre são atendidas por obras de caráter mais geral que não levam em consideração esse importante grupo de usuários. Isso talvez ajude a explicar por que tantos tradutores participem de projetos lexicográficos.

Muitos estudos sobre lexicografia bilíngue enfocam características dos dicionários propriamente ditos, como suas macro- e microestruturas, forma de apresentação, métodos para elaboração dos verbetes, ferramentas disponíveis (ATKINS; RUNDELL, 2008; GRANGER, 2012).Também há um bom repertório de estudos sobre lexicografia bilíngue histórica realizados por pesquisadores portugueses e brasileiros (VERDELHO, 2002 e 2011; DO CARMO et al., 2019; BIDERMAN, 1984 e 2002; NUNES, 2002; KRIEGER et al., 2006).No campo da História da Tradução, por outro lado, com a honrosa exceção do capítulo "Os tradutores e os dicionários", no volume Tradutores na história, organizado por Jean Delisle e Judith Woodsworth (2012), não identifiquei outros estudos que ressaltassem o papel da tradução e dos tradutores na elaboração de dicionários.

Assim, a partir de dados extraídos de prefácios das obras analisadas, entrevistas e depoimentos dos autores e tradutores especializados, colhidos em blogs de tradutores, sites de editoras ou anais de congressos, pretendo mostrar quem foram/são os tradutores autores dos dicionários selecionados, aqui chamados de tradutores lexicógrafos, que tanto contribuíram e contribuem para a melhoria da qualidade das traduções em geral e das especializadas em particular.

\section{Pressupostos metodológicos}

Tendo como abordagem teórica a perspectiva apresentada por Pym (2014), adaptarei os questionamentos feitos por ele quando procurou delinear um método que respaldasse suas reflexões teóricas sobre a história da tradução. 
Pym apresenta quatro princípios básicos que norteiam seu trabalho: por que as traduções são produzidas em determinado momento social e local (relações de causa e efeito sociais); o objeto central do conhecimento histórico deve ser o tradutor humano e seu contexto social (clientes, patronos, leitores); os tradutores tendem a ser interculturais, ou seja, vivem e trabalham na interseção ou sobreposição de culturas diferentes; e qualquer história da tradução deve ter como ponto de partida o momento presente (PYM, 2014, p. ix-x).

Para ele, a história da tradução é um "conjunto de discursos" abrangendo ações e agentes que geraram traduções (ou não traduções), os efeitos das traduções (ou não traduções), as teorias de tradução e uma longa lista de fenômenos causais relacionados (p. 5). Pym propõe três subdivisões de discursos que, segundo ele, ajudam a organizar a pesquisa: arqueologia, crítica e explicação. A arqueologia está centrada em responder perguntas do tipo "quem traduziu o que, como, onde, quando, para quem e com que efeito". A crítica histórica avalia como as traduções ajudaram ou atrapalharam o progresso em determinado período no passado. A explicação pretende responder a pergunta que Pym considera mais importante: "por quê?", pois abrangeria a dimensão humana e as relações de causa e efeito capazes de explicar os processos de mudança, uma vez que lança foco nas relações de poder e revela os tradutores humanos como verdadeiros agentes sociais.

É justamente para escrever essa história da tradução baseada nos tradutores que o autor reforça a necessidade de uma metodologia que abarque também tudo que já foi escrito e pensado nesse campo. Para ele, a integração das diferentes explicações, uma arqueologia propriamente empírica e a historicização da teoria são elementos essenciais que não podem ser ignorados. Pym justifica a sua busca afirmando que, à época em que seu volume foi originalmente publicado, em 1998, havia uma história incipiente dos tradutores, que prestava pouca atenção ao método, e uma teoria de sistemas, que prestava pouca atenção aos tradutores (PYM, 2014, p. 15). Ele justifica, assim, seu desejo de elaborar um método que dialogue com essas diferentes visões e com a própria história das teorias de tradução. Ao delinear suas expectativas para o futuro, Pym deixa claros os motivos pelos 
quais ele se debruça sobre o estudo da história da tradução, sempre focado no papel do tradutor como intermediário intercultural. Olhar para o passado é a melhor forma de iluminar o caminho para o futuro. Nesse futuro, a história da tradução baseada em uma história dos tradutores pode ter, sim, um papel relevante, sobretudo em um mundo globalizado e totalmente interligado.

Como muito bem ressaltado por José Antonio Sabio Pinilla (2020), em artigo que trata da História da Tradução no Brasil, esse campo é relativamente novo nos Estudos da Tradução, em que o interesse pelos estudos historiográficos se desenvolveu ao longo da década de 1990. Pinilla cita a tradutora, professora e pesquisadora da área de tradução Lia Wyler como o "primeiro grande nome da pesquisa histórica da tradução brasileira" (p. 17). Depois de fazer uma revisão bibliográfica dos estudos realizados no país até hoje, o autorafirma que há um predomínio de visões panorâmicas, menos aprofundadas, e que a tarefa à frente é ainda imensa, ou seja, há muitos caminhos de pesquisa a percorrer, com "mais perguntas que respostas". Dentre os temas a serem explorados nesta seara estão "a história dos tradutores: abordagem individual, por geração, escola ou grupo. Os filólogos e a tradução" (p. 23).

Acredito que minha pesquisa possa constituir um primeiro passo para o aprofundamento da história dos dicionários bilíngues no Brasil e, principalmente, para outros estudos sobre o envolvimento de tradutores na produção lexicográfica de períodos históricos específicos.

Assim, proponho uma "arqueologia" aos moldes de Pym (2014), para revelar um pouco sobre a vida dos tradutores autores de dicionários selecionados (oito autores de obras produzidas a partir da segunda metade do século $\mathrm{XX}$ ): o que traduziram e se têm obras próprias, como, onde, quando, para quem, com que efeito e por que suas obras foram produzidas, ecoando também D'hulst $(2001,2010)$, que propõe uma lista de perguntas (quis? quid? ubi? quibus auxiliis? cur? quo modo? quando?) para orientar pesquisas de cunho historiográfico.

Para traçar essa "arqueologia" dos tradutores lexicógrafos, parti do capítulo dedicado aos dicionários, escrito por Jean-Claude Boulanger, no volume de Delislee Woodsworth (2012). Nesse capítulo, o autor resume em 
poucas páginas séculos da história ocidental até os dias atuais, tendo como fio condutor a relação entre os tradutores e os dicionários, em que ora tradutores atuam como lexicógrafos, ora lexicógrafos atuam como tradutores (BOULANGER, 2012, p. 223). Pela própria característica do volume, a maioria dos exemplos é de língua inglesa e francesa e apenas uma obra em que o português figura é mencionada. Entre os lexicógrafos tradutores destacados por Boulanger, estão William Caxton (1422-1491), Samuel Johnson (1709-84) e Emile Littré (1801-81), além de vários outros em diferentes idiomas e períodos históricos (excluindo o português).

\section{Brevíssimo panorama histórico}

A história dos dicionários é tão antiga quanto a história da própria escrita (e da tradução), grandes conquistas intelectuais da humanidade. Foram necessários séculos para a passagem das primeiras listas de palavras (a partir de 3.000 AEC - sumérios e suas tabuletas) aos glossários medievais e depois aos dicionários bi-, multi- e monolíngues das línguas nacionais a partir do século XVI até os dias de hoje. Podemos resumir essa evolução também pela tecnologia empregada: das tabuletas de argila a papiros, pergaminhos, papel, discos, disquetes, CDs, DVDs, pen-drives e sites da internet.

Portugal acompanha a evolução lexicográfica da Europa de forma mais lenta e com dimensão mais modesta, por ser um espaço linguístico periférico e de pequeno peso demográfico (VERDELHO, 2011, p. 13). Da mesma forma que os dicionários da maior parte das línguas modernas, o primeiro da língua portuguesa também é bilíngue: o Dictionarium ex lusitânico in latinum sermonem, de Jerónimo Cardoso, publicado em Lisboa em 1562. Esse dicionário é um marco para a lexicografia portuguesa, uma vez que se trata da primeira nomenclatura em língua portuguesa, composta por 12.000 palavras, ordenadas alfabeticamente na direção português-latim, palavras essas que serão retomadas, na quase totalidade, pela tradição dicionarística portuguesa até o presente (VERDELHO, 1991, p. 298).

Segundo Verdelho (2011, p. 6), como acontecera já com os dicionários de latim-português, o pareamento do português com as línguas modernas, como o francês, o inglês e o italiano, suscitou a transferência do vocabulário referente à ciência e à tecnologia e ofereceu modelos de criatividade lexical e 
de formação de palavras, provendo o corpus lexical com novos recursos de expressão. Além disso, a lexicografia bilíngue intensificou o relacionamento e a intercomunicação com o público brasileiro, que, até o fim do século XIX, tinha acesso especialmente a obras luso-francesas e luso-inglesas (em menor escala).

O Brasil entra na cena lexicográfica pouco tempo após o seu achamento, no século XVI, com a gramática e os dicionários do portuguêstupi elaborados pelos missionários jesuítas, como a Arte da gramática na língua mais usada na costa do Brasil, do Padre José de Anchieta, publicada em Coimbra em 1595. O padre José de Anchieta é autor de várias obras multilíngues, envolvendo português, castelhano, latim e tupi (WYLER, 2003, p. 63). Enquanto em Portugal, o primeiro dicionário contempla o português e o latim, no Brasil, o primeiro é entre português e tupi. No Japão e na China, missionários portugueses também geram versões bilíngues nas combinações português-japonês e português-chinês, como instrumentos de catequese e colonização, levando o alfabeto latino a essas culturas orientais.

José Horta Nunes, no capítulo dedicado à dicionarização no Brasil que integra o volume História do saber lexical e constituição de um léxico brasileiro (2002), resume muito bem as condições de produção dos dicionários no Brasil, respondendo a perguntas essenciais do ponto de vista histórico: "quem produz o dicionário, como, onde, para quem e em que circunstâncias?" (NUNES, 2002, p. 107). Sua análise é muito rica e está focada na produção dos dicionários monolíngues, mas também reforça o protagonismo dos bilíngues, que, segundo o autor, "serviram de matériaprima para a constituição dos monolíngues" (p. 102).

O século XIX no Brasil tem vários acontecimentos marcantes, incluindo a chegada da Família Real portuguesa, o estabelecimento da imprensa, a fundação da Biblioteca Nacional e dos primeiros jornais brasileiros (Gazeta do Rio de Janeiro e Correio Brasiliense), a Independência do Brasil, a fundação do Colégio Pedro II (marcando o início da escolarização pública), a Proclamação da República e a fundação da Academia Brasileira de Letras, para mencionar apenas alguns. A produção dicionarística do período também foi farta, incluindo dicionários de tupi-português, de regionalismos e brasileirismos (NUNES, 2002, p. 105-106). 
Dentre vários outros dicionários bilíngues publicados a partir da segunda metade do século XIX, o destaque é para o Dicionário Michaelis inglês-português (1893), elaborado pela lexicógrafa alemã Henriette Michaelis, em colaboração com sua irmã Carolina Michaelis de Vasconcelos, figura importante nos estudos filológicos em Portugal. O dicionário teve grande aceitação no Brasil ao longo do século XX e se mantém atualizado até hoje, sendo que, em 1950, passou a ser editado pela Editora Melhoramentos (DO CARMO et al., 2019, p. 150). A atuação de Henriette Michaelis como tradutora não pôde ser comprovada, porém merece menção por ser a única mulher em uma longa lista de lexicógrafos do sexo masculino, em um período em que poucas conseguem destaque.

Somente no século XX temos o início formal da lexicografia brasileira (KRIEGER, 2006, p. 173), e sua consolidação se dá apenas na segunda metade desse século, com os dicionários de língua portuguesa de Antenor Nascentes (1961), Aurélio Buarque de Holanda (1975) e Antônio Houaiss (2001), tendo esses três lexicógrafos também atuado como tradutores, com várias obras traduzidas. Esse também é um período fértil de produção dos primeiros dicionários bilíngues inglês-português especializados, com o lançamento das obras de Eugênio Fürstenau (1946), Lewis Sell (1953), Luiz Mendes Antas (1979), entre outras.

É no período entre 1950 e 1980 que podemos dizer que o mercado de tradução técnica se desenvolve de fato no Brasil, muito em função do plano desenvolvimentista de Juscelino Kubitschek (com a construção de rodovias, centrais de energia e indústrias de bens de consumo) e em que as editoras nacionais se aliam a parceiras internacionais, traduzindo um número considerável de obras enciclopédicas, sob supervisão e com a colaboração de centenas de tradutores (WYLER, 2003, p. 136-137). Algumas coleções que se destacam são: Mundo das crianças (1954), Enciclopédia Delta-Larousse (1960), a Grande Enciclopédia Delta-Larousse (1979), a Enciclopédia Barsa (1964) e a Enciclopédia Mirador Internacional (1974). Cunha (2020) faz uma análise histórica das enciclopédias, apresentando as principais disponíveis hoje - em formato digital - e pondera que "a migração do formato impresso para o digital parece irreversível" (p. 5). 
As primeiras décadas do século XXI viram surgir os primeiros dicionários mono- e bilíngues publicados inteiramente on-line, ou seja, em versão digital, sem correspondente em papel. Este é o caso, por exemplo, da linha de dicionários Michaelis, disponível gratuitamente no portal https://michaelis.uol.com.br/: o monolíngue Michaelis Dicionário Brasileiro da Lingua Portuguesa (com 167 mil verbetes) e os bilíngues (sempre em combinação com o português). Um aspecto muito interessante é o crédito dado à equipe editorial em cada idioma, algo incomum em boa parte das obras do tipo.

Atualmente, os dicionários das principais línguas modernas estão disponíveis on-line gratuitamente e existem também sites que, além da opção do dicionário bilíngue, oferecem a tradução automática direta dos termos pesquisados, como o Google Tradutor (cujo aplicativo pode, inclusive, ser baixado para uso no celular), e outros que oferecem exemplos de uso dos termos em contexto, como é o caso do Linguee. Sem contar os portais de terminologia bilíngue especializada como os da Microsoft (informática) ou Anacpédia (aviação), entre inúmeros outros. Tudo isso contribuiu para uma redução das publicações impressas, substituindo as reimpressões em papel por versões digitais (e-books) ou impressões sob demanda.

\section{Os tradutores e seus dicionários}

Oito tradutores lexicógrafos e suas obras foram selecionados para este estudo, o que, por si só, já revela que há muito campo ainda por investigar e inúmeras outras obras a incluir, não só no par inglês-português, mas também em todas as outras possíveis combinações de idiomas e modalidades. São eles: Leonel Vallandro, Antônio Houaiss, James L. Taylor, Eugênio Fürstenau, Luiz Mendes Antas, Marcia Buckley, Marcílio Moreira de Castro e Ana Júlia Perrotti-Garcia.

Como características gerais das obras escolhidas, podemos dizer que todas foram resultado de longos anos de compilação, fruto de trabalho minucioso de pesquisa dos respectivos autores, que, em sua quase totalidade, não contaram com equipes para auxiliá-los. Os dicionários constam do Acervo de Referência da Biblioteca Nacional (https://www.bn.gov.br/explore/acervos/referencia), que constitui fonte 
preciosa de consulta, contendo informações sobre as diferentes edições e datas de publicação.

A ordem em que são apresentados é cronológica (do mais antigo para o mais recente), sempre que possível incluindo dados biográficos, foto e informações adicionais sobre a produção de cada tradutor lexicógrafo. Além da divisão entre dicionários bilíngues gerais e especializados, uma outra divisão é necessária: os produzidos e editados entre as décadas de 1940 e 1980 em papel, englobando vários domínios, e os produzidos e editados a partir da década de 1990 até os dias de hoje, com versões digitais e maior grau de especialização. Sempre que disponível, procurei incluir a data da primeira edição dos dicionários para marcar a época em que foram publicados e indico também a última edição.

Como fonte de consulta para encontrar obras próprias e traduzidas de alguns dos tradutores lexicógrafos elencados aqui, o Dicionário de tradutores literários do Brasil - DITRA, criado pela PGET (Pós-graduação em Estudos da Tradução da Universidade Federal de Santa Catarina) foi de grande valia. Nomes como Aurélio Buarque de Holanda, Paulo Rónai e Rena Signer também estão entre os tradutores lexicógrafos com biografias retratadas na página - todos com extensa lista de obras traduzidas e uma significativa produção lexicográfica, os dois últimos com dicionários bilíngues francês-português, fora do escopo do presente estudo.

\subsection{Dicionários bilíngues inglês-português gerais}

\subsubsection{Leonel VALLANDRO (1907-?); Lino VALLANDRO: Dicionário} inglês-português. Porto Alegre: Editora Globo, 1954 (cerca de 60 mil verbetes; republicado pelo menos nove vezes até 1979). Disponível como livro usado em sebos virtuais. 


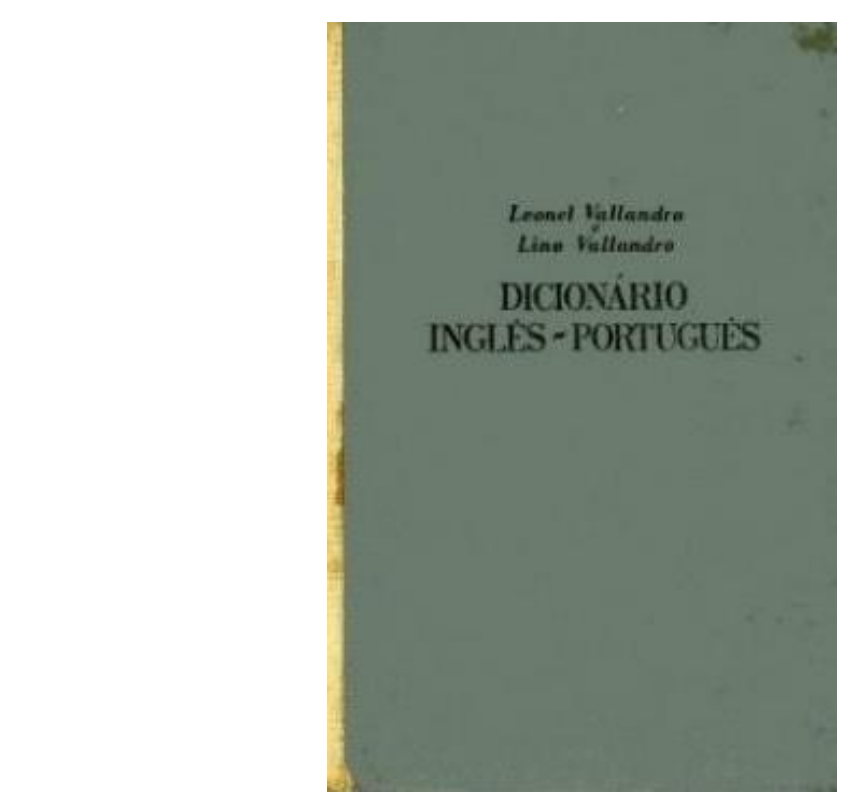

Figura 1: Capa da edição de 1962 do Dicionário inglês-português, de Leonel Vallandro e Lino Vallandro, publicado pela Editora Globo.

O primeiro da lista é o dicionário bilíngue de Leonel Vallandro, autor escolhido por ter um grande número de obras traduzidas, conforme comprovado pela lista publicada no DITRA (HANES; GUERINI, 2013), complementada pela lista compilada pela tradutora Denise Bottman, disponível em seu blog Não gosto de plágio. A mão de Fu-Manchu, de Sax Rohmer, consta como primeira tradução de Leonel Vallandro, publicada como o volume 17 da Coleção Amarela da Livraria do Globo, em 1932. O ano de 1976 está indicado como provável ano de publicação de suas últimas traduções.

Sua carreira como tradutor esteve estreitamente relacionada com a história da Editora Globo de Porto Alegre, que o contratou em tempo integral como parte de seu pessoal especializado para a realização de traduções. Segundo Hallewell (1985, p. 406-407), Vallandro era um "modesto tradutor de novelas policiais e foi promovido a encarregado da tradução de obras literárias em reconhecimento da superior qualidade do seu trabalho". Dentre os autores traduzidos, estão Agatha Christie, Graham Greene, Somerset Maugham, Ian Fleming, James Hadley Chase, Arthur Clarke, Alfred Hitchcock, entre outros. Seu dicionário foi escrito em parceria com o irmão 
Lino, que também era tradutor na Editora Globo. Wyler (2003, p. 130) caracteriza a obra como "inigualável".

Infelizmente, não foi possível obter mais informações sobre a biografia de Leonel Vallandro, nem sobre como se deu a produção do dicionário. No entanto, como a obra foi publicada pela Editora Globo, podemos supor que tenha sido elaborada ao longo dos anos de trabalho dos autores na editora. Também não foi possível encontrar fotos nem mesmo o registro de seu falecimento.

\subsubsection{Antônio HOUAISS (1915-1999): Webster's dicionário inglês-} português. Rio de Janeiro: Record, 1982. Em colaboração com Ismael Cardim. Mais de 100 mil verbetes. Disponível como livro usado em sebos virtuais.

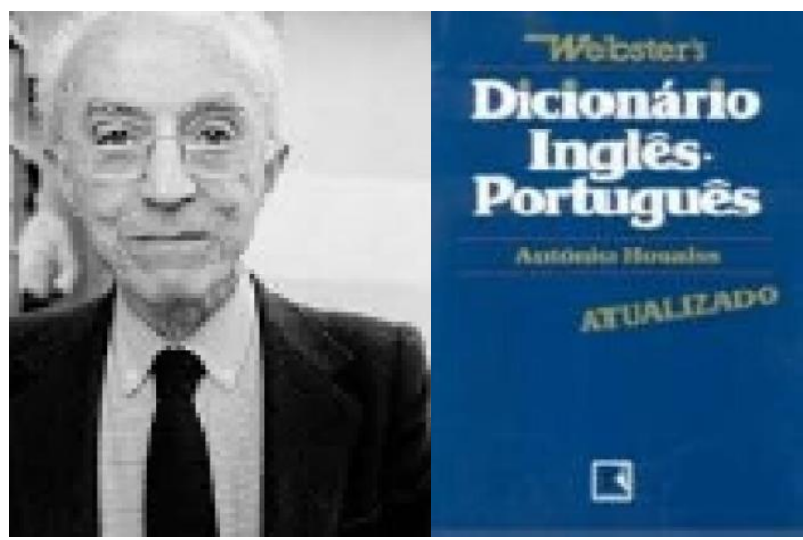

Figura 2. Foto de Antônio Houaiss e capa da 16 edição, publicada em 2006 pela editora Record.

Antônio Houaiss foi filólogo, lexicógrafo, tradutor, crítico literário, professor e diplomata, colaborador de dicionários bilíngues inglêsportuguês (Barsa, Webster's) e responsável pela coordenação da edição brasileira da Encyclopaedia Britannica, da Enciclopédia Mirador Internacional e da Grande Enciclopédia Delta-Larousse, organizadas em um espaço de dez anos (1964-1974). Destaca-se como tradutor de James Joyce, responsável pela 
primeira tradução brasileira desse autor, de importância reconhecida por todos os profissionais da área ${ }^{1}$.

O dicionário bilíngue Webster's foi incluído neste estudo por representar uma obra que, à época em que foi lançada (1982), pretendia ser a "mais copiosa" do mercado até aquela data, como consta em seu prefácio. Visa ser um "instrumento completo" para a tradução do inglês - de qualquer região - para o português em sua modalidade escrita. Houaiss considera seu trabalho como contribuindo para a prestação de um "serviço de monta ao avanço cultural dos países de língua portuguesa". Sem dúvida, ao considerar que seu dicionário era um instrumento para tradução, o autor priorizou os tradutores como público-alvo de sua obra.

Houaiss, à época da elaboração do dicionário, era já renomado como filólogo, lexicógrafo e tradutor e contou com uma equipe também composta por colaboradores e redatores envolvidos direta ou indiretamente com a tradução, incluindo as professoras de língua e literatura inglesa e de tradução Peônia Viana Guedes e Branca Telles Ribeiro, o escritor e tradutor Carlos Sussekind e o tradutor José E. A. do Prado.

Peônia V. Guedes e Branca T. Ribeiro, em um breve artigo elaborado para apresentação no IV Congresso Nacional de Linguística e Filologia em Homenagem a Antônio Houaiss, realizado em 2000, refletem sobre os desafios envolvidos em um projeto de dicionário bilíngue e contam que a equipe teve um prazo de dezoito meses para a elaboração e redação do dicionário, trabalhando com três lexicógrafos em tempo integral e dois em tempo parcial, na sede da Editora Record. Nesse artigo, as autoras detalham os critérios adotados pelo grupo supervisionado por Houaiss para preparação dos verbetes: seriam consultados os dicionários elaborados pelos irmãos Vallandro, Dicionário Inglês-Português (um volume), o Novo Michaelis Dicionário Ilustrado (dois volumes) e o Novo Dicionário Barsa (dois volumes, parte integrante da Enciclopédia Britânica). Além desse material, seriam consultados dicionários monolíngues e bilíngues de expressões idiomáticas, gíria e termos técnicos, bem como glossários técnicos especializados em

\footnotetext{
${ }^{1}$ Disponível em: <http://enciclopedia.itaucultural.org.br/pessoa14496/antonio-houaiss>. Acesso em: 16 jun. 2020. Verbete da Enciclopédia. ISBN: 978-85-7979-060-7.
} 
áreas de conhecimento recente, ainda não incorporadas aos dicionários existentes (como, por exemplo, termos de informática, bioengenharia, genética, psicanálise, entre outros). Muito interessante encontrar esse relato, uma vez que essa informação não consta do próprio dicionário. A seguir, uma breve lista de sua produção lexicográfica e de obras traduzidas.

Tabela 1. Obras de Antônio Houaiss

\begin{tabular}{|c|c|}
\hline xicográficas: & Traduções \\
\hline $\begin{array}{l}\text { Novo Dicionário Barsa das Línguas } \\
\text { Inglesa e Portuguesa. Rio de Janeiro: } \\
\text { Encyclopaedia Britannica, 1964. Em } \\
\text { colaboração com Catherine B. } \\
\text { Avery. }\end{array}$ & $\begin{array}{l}\text { Joyce, James. Ulisses [Ulysses]. Rio } \\
\text { de Janeiro: Civilização Brasileira, } \\
1966 .\end{array}$ \\
\hline $\begin{array}{l}\text { New Appleton Dictionary of English } \\
\text { and Portuguese Languages. New } \\
\text { York: Appleton-Century-Crofts, } \\
\text { 1967. }\end{array}$ & $\begin{array}{l}\text { Joyce, James. Ulisses [Ulysses]. } 14^{\underline{a}} \\
\text { ed. Rio de Janeiro: Civilização } \\
\text { Brasileira, 2004. }\end{array}$ \\
\hline $\begin{array}{l}\text { Pequeno Dicionário Enciclopédico } \\
\text { Koogan-Larousse. Rio de Janeiro: } \\
\text { Larousse, } 1979 .\end{array}$ & $\begin{array}{l}\text { Joyce, James. O gato e o diabo [The cat } \\
\text { and the devil]. Rio de Janeiro: Record, } \\
1995 .\end{array}$ \\
\hline $\begin{array}{l}\text { Exitus Dictionary of the English and } \\
\text { Portuguese Languages. New Jersey: } \\
\text { Prentice-Hall, } 1983 .\end{array}$ & $\begin{array}{l}\text { Shuster, Jean. Os arcanos maiores da } \\
\text { poesia surrealista e sua exaltação [Les } \\
\text { arcanes majeurs de la poesie surrealiste } \\
\text { et leur exaltation]. São Paulo: } \\
\text { Brasiliense/Aliança Francesa, } 1988 \text {. }\end{array}$ \\
\hline 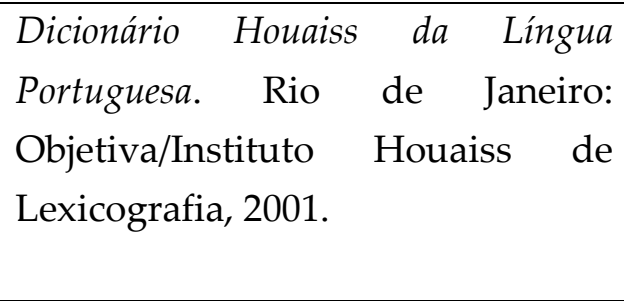 & $\begin{array}{l}\text { Sayers, Raymond S. O negro na } \\
\text { literatura brasileira. [The negro in } \\
\text { Brazilian literature] Tradução e notas } \\
\text { de Antônio Houaiss. Rio de Janeiro: } \\
\text { Edições O Cruzeiro, } 1958 \text {. }\end{array}$ \\
\hline
\end{tabular}




\subsubsection{James Lumpkin TAYLOR (1892-1983):}

- Portuguese-English Dictionary. Rio de Janeiro: Record, 1982. Disponível como livro usado em sebos virtuais.

- Dicionário Metalúrgico: Inglês-Português, Português-Inglês.1ำ ed., São Paulo: Associação Brasileira de Metais, 1976. Disponível como livro usado em sebos virtuais.

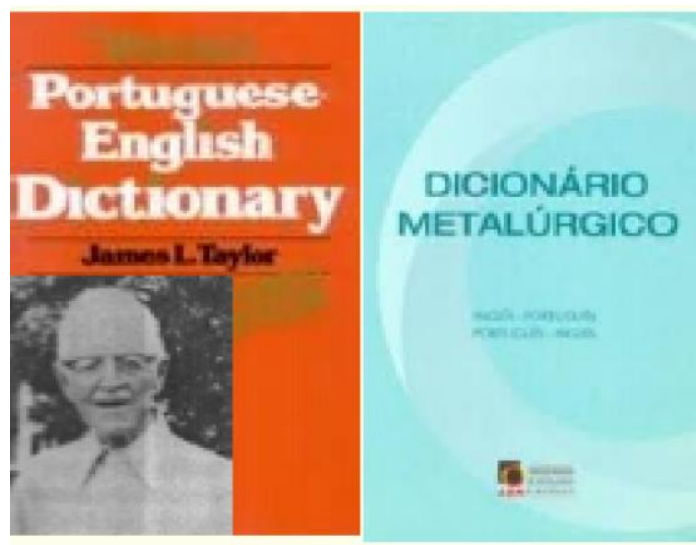

Figura 3. Foto de James L. Taylor e capas dos dicionários de sua autoria: PortugueseEnglish Dictionary, 16 ${ }^{\mathrm{a}}$ edição revisada, publicada pela Editora Record em 2007, e Dicionário Metalúrgico: Inglês-Português, Português-Inglês, 2ª edição revisada e ampliada, publicada pela ABM em 2000.

James L. Taylor foi professor de estudos latino-americanos na Universidade de Stanford, na Califórnia, sócio honorário da Associação Brasileira de Metais (ABM), professor de línguas, lexicógrafo e tradutor. Trabalhou na fundição da Cia. Lidgerwood em São Paulo e, na Primeira Guerra Mundial, serviu no exército americano como secretário particular do General Pershing. Além disso, foi Comandante da Força Expedicionária Americana. Após o conflito, voltou ao Brasil para trabalhar na Consolidated Steel Co., na comercialização de produtos siderúrgicos dos EUA.

Cunha (2020, p. 83) considera o Portuguese-English Dictionary uma obra clássica, com 655 páginas e cerca de 60 mil verbetes. Foi publicado pela primeira vez em 1958, pela Stanford University Press e reimpresso com alterações e acréscimos em 1963 e 1970. Na apresentação da primeira edição, 
Taylor descreve alguns critérios que orientaram as suas escolhas na compilação do dicionário e afirma ter incluído para cada verbete em português equivalentes em inglês, sinônimos e exemplos de uso, além de termos técnicos das artes e ciências e nomenclaturas da fauna e flora brasileiras, com os respectivos nomes científicos. A obra inclui, ainda, expressões idiomáticas, gírias da época, definições e breves explicações quando determinado termo ou conceito não tem equivalente direto em inglês, seções sobre gramática e ortografia e um apêndice de verbos. Seu objetivo é claramente o de facilitar o entendimento do português por parte do falante de língua inglesa, mas a obra também está voltada para tradutores que vertem textos para o inglês. Segundo o próprio autor, sua intenção é preencher uma lacuna, uma vez que já havia no mercado brasileiro (desde 1950) bons dicionários inglês-português, como o de Vallandro (de 1954), mas não de português-inglês, com exceção do dicionário português-inglês Michaelis, cujo teor, segundo Taylor, estava datado. Além disso, o dicionário ainda inclui uma lista das obras de referência utilizadas na sua elaboração.

A Editora Record é responsável pela edição no Brasil, sendo a primeira em 1982 e a última, em 2007, segundo os registros do acervo da Biblioteca Nacional. Antônio Houaiss, no Prefácio do seu Dicionário InglêsPortuguês, afirma que o dicionário de Taylor é "altamente bem cotado pelos entendidos e pelos usuários" e que há um "deliberado esforço" no sentido de que as obras sejam complementares.

Além de constar da lista de obras consideradas relevantes para o público brasileiro, elaborada por Cunha (2020, p. 83), o trabalho de Taylor na compilação desse dicionário foi reconhecido pelo governo brasileiro, que lhe concedeu a Ordem do Cruzeiro do Sul, conferida a estrangeiros que se destacam no país. Essa informação consta das Notas do Editor, nas primeiras páginas de outra obra lexicográfica de peso de Taylor e bastante significativa para quem trabalha com tradução especializada, por incluir termos da indústria siderúrgica e áreas afins: o Dicionário Metalúrgico InglêsPortuguês/Português-Inglês. A primeira edição desta obra é de 1963, sendo a parte em português acrescentada em 1976, passando a ser editada pela Associação Brasileira de Metais em 1985. A última edição é de 2004 e já conta 
com a colaboração de Vicente Chiaverini, engenheiro e professor da Escola Politécnica da USP.

Seu lado bem menos conhecido é de tradutor literário, embora tenha traduzido para o inglês duas obras importantes da literatura brasileira, Grande sertão: veredas, de Guimarães Rosa (JACKSON, 2002, p. 135) e Gabriela cravo e canela, de Jorge Amado (TOOGE, 2009). Ao que parece, sua incursão pelo mundo literário não foi muito bem recebida pela crítica. Tooge (2009) e Jackson (2002) apontam problemas em suas versões das obras.

Já a tradução para o inglês do livro A História do Brasil Moderno, 18891964, de José Maria Bello, foi publicada pela Stanford University Press e obteve o apoio da bolsa Rockefeller do Programa Latino-Americano de tradução, da Fundação Rockfeller, através da mobilização da Associação de Editoras Universitárias Americanas.

Tabela 2. Obras de James L. Taylor

\begin{tabular}{|c|c|}
\hline Obras lexicográficas & $\begin{array}{c}\text { Traduções publicadas para o } \\
\text { inglês: }\end{array}$ \\
\hline $\begin{array}{l}\text { Portuguese-English Dictionary. Rio de } \\
\text { Janeiro: Record, } 1982 .\end{array}$ & $\begin{array}{l}\text { Jorge Amado. Gabriela, Clove and } \\
\text { Cinnamon [Gabriela, cravo e canela]. } \\
\text { Tradução de James L. Taylor e } \\
\text { William Grossman. Nova York: } \\
\text { Knopft, 1962. }\end{array}$ \\
\hline \multirow[t]{2}{*}{$\begin{array}{l}\text { Dicionário } \quad \text { Metalúrgico: } \quad \text { Inglês- } \\
\text { Português, Português-Inglês. } 1^{\underline{a}} \text { ed., } \\
\text { São Paulo: Associação Brasileira de } \\
\text { Metais, 1976. }\end{array}$} & $\begin{array}{l}\text { João Guimarães Rosa. The Devil to } \\
\text { Pay in the Backlands [Grande sertão: } \\
\text { veredas]. Tradução de James L. } \\
\text { Taylor e Harriet de Onís. Nova } \\
\text { York: Knopft, } 1963 \text {. }\end{array}$ \\
\hline & $\begin{array}{l}\text { José Maria Bello. A History of } \\
\text { Modern Brazil, 1889-1964[A História } \\
\text { do Brasil Moderno, 1889-1964]. } \\
\text { Stanford: Stanford University } \\
\text { Press, 1966. }\end{array}$ \\
\hline
\end{tabular}


4.2 Dicionários bilíngues inglês-português especializados compilados até 1980

Os dois próximos dicionários selecionados podem ser considerados clássicos uma vez que vêm sendo utilizados por várias gerações de tradutores e contemplam um número surpreendente de verbetes, considerando a época em que foram escritos, com poucos ou inexistentes recursos computacionais disponíveis quando teve início o trabalho de compilação e redação das respectivas obras. Abarcam várias áreas do saber, com indicação dos diferentes subdomínios. As duas obras foram elaboradas por tradutores técnicos, pelo pouco que consegui obter de sua produção tradutória, o que explica em certa medida sua invisibilidade como tradutores, como a falta de fotos ou dados biográficos.

\subsubsection{Eugênio FÜRSTENAU (1913-1986): Novo dicionário de termos} técnicos inglês-português.26 $6^{\mathrm{a}}$ ed. São Paulo: Globo, 2007, 2 volumes. Disponível como livro usado em sebos virtuais.

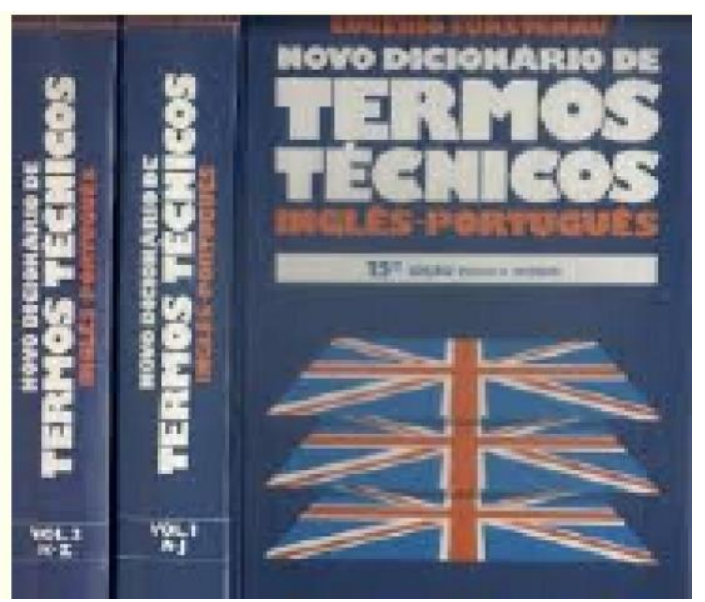

Figura 4. Capa da 24ª edição do Novo dicionário de termos técnicos inglês-português, publicado pela Editora Globo, em 2008.

Eugênio Fürstenau foi tradutor de obras técnicas, primeiro para a editora Gertrum Carneiro (década de 1940, cf. Labanca, 2009) e depois para a Editora Globo. 
Segundo Hallewell (1985, p. 407), a Editora Globo tinha, desde 1930, tinha interesse na publicação de obras mais técnicas, que "parece ter crescido naturalmente a partir do envolvimento com a tradução". Eugênio Fürstenau é citado como lexicógrafo da Editora Globo, responsável pelo Dicionário de Termos Técnicos Inglês-Português. A obra é editada desde 1946, acompanhando a evolução da ciência e tecnologia. Inclui mais de 100 mil verbetes, mencionando a área a que pertencem.

O prefácio da edição revista e ampliada de 1985, publicada quando o autor ainda vivia, revela que a obra em questão foi resultado do trabalho realizado por ele entre abril de 1973 e janeiro de 1985: “durante este período, completou esta obra 45 anos de trabalho de organização, pois em 1940 foram preparadas as primeiras fichas que viriam a integrar o Dicionário de Termos Técnicos." Um agradecimento especial é dirigido aos colaboradores que enviaram "listas de termos especializados de suas atividades que não encontraram nos dicionários existentes" (n.p.).

\subsubsection{Luiz Mendes ANTAS (1928-2010): Dicionários Técnicos Inglês-} Português e Português-Inglês. São Paulo: Traço Editora (Coleção Aeroespacial). Disponível como livro usado em sebos virtuais.
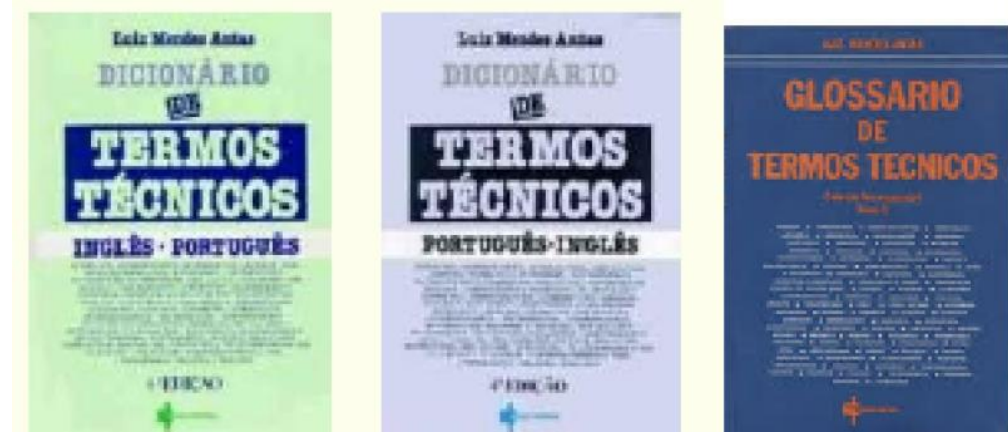

Figura 5. Capas das obras da Coleção Aeroespacial, de Luiz Mendes Antas, editada pela Traço Editora: Dicionário Técnico Inglês-Português, $6^{\mathrm{a}}$ edição, 2000; Dicionário Técnico Português-Inglês, $4^{a}$ edição, 2000; e Glossário de Termos Técnicos, 1979.

Luiz Mendes Antas era licenciado em Ciências Meteorológicas pela Faculdade de Ciências Exatas da Universidade de Buenos Aires e Oficial 
Meteorologista da Força Aérea Brasileira, tendo ingressado na FAB em 1945, seguindo carreira militar até sua reserva, no início da década de 1980.

Em depoimento homenageando Antas, um colega militar resume suas realizações: “Depois de traduzir livros, manuais e documentos técnicos, ele passou a traduzir clássicos da Ciência Meteorológica, com nada menos do que 16 volumes. Foram Glossários, Dicionários e Vocabulários, em inglês e espanhol, além de traduções para a USAID e para a Abril Cultural. Organizou, estruturou e escreveu a maior coleção de dicionários de Ciências Espaciais e Aeronáuticas existente no Brasil por conta própria, sem colaboradores ou financiamentos" (SILVA, 2007, n.p.).

O mesmo texto retrata Antas como "solitário", que trocava as manhãs de sol por "mesas cheias de livros, manuais, documentos técnicos e, principalmente, dicionários de várias línguas" (SILVA, 2007, n.p.). Em 2005, Antas completou 60 anos dedicados à Meteorologia. Graças a esse breve depoimento e ao fato de Antas ter sido Oficial da FAB, foi possível saber um pouco mais sobre esse tradutor lexicógrafo, pois nem mesmo o acervo da Biblioteca Nacional contém informações, como datas de nascimento e falecimento.

A ficha de Antas constante dos boletins da Aeronáutica contém datas importantes em sua carreira militar, incluindo condecorações:

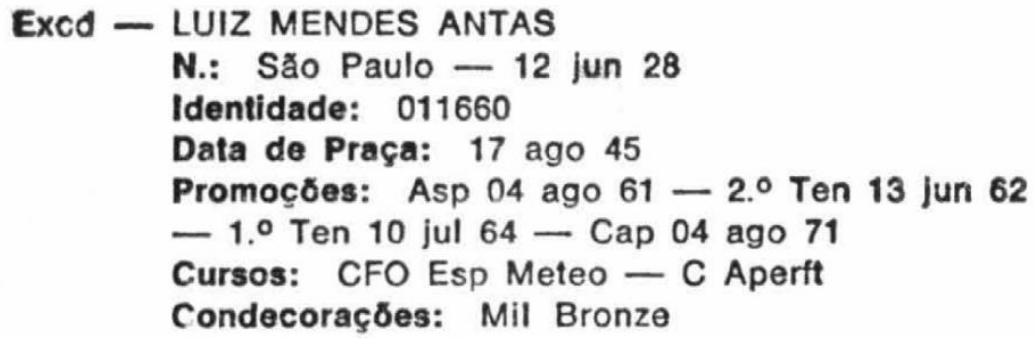

Fonte: Boletim Informativo dos Inativos e Pensionistas da Aeronáutica e Almanaque 1976 - Oficiais da Aeronáutica - Pessoal - Oficiais. 
Tabela 3. Obras de Luiz Mendes Antas

Obras lexicográficas:

Glossário de termos técnicos. São Paulo: Traço Editora, 1979, Tomo I da Coleção Aeroespacial. Ordenado alfabeticamente em português, com definições em português e equivalentes em inglês.

Dicionário de termos técnicos inglês-português. 6 $6^{\text {a }}$ ed. São Paulo: Traço Editora, 2009. Arrola termos de 50 áreas técnicas. Tomo II da Coleção Aeroespacial.

Dicionário de termos técnicos português-inglês. $4^{\mathrm{a}}$ ed. São Paulo: Traço Editora, 2000. Arrola termos de uso internacional em 50 áreas técnicas. Tomo III da Coleção Aeroespacial.

Dicionário de termos técnicos de meio ambiente: inglês-português, portuguêsinglês. São Paulo: Traço Editora, 2006. Série: Coleção Aeroespacial.

Dicionário de siglas e abreviaturas. 3a ed. São Paulo: Traço, 2010. Apresenta siglas e abreviaturas brasileiras utilizadas até meados da primeira década do século XXI.

Obras traduzidas:

Manual de meteorologia para pilotos - MMA-DR-105-02. Rio de Janeiro, Ministério da Aeronáutica - Diretoria de Rotas Aéreas / USAID, 1966.

Manual de meteorologia para aeronavegantes - MMA-DR-105-03. Rio de Janeiro, Ministério da Aeronáutica / USAID, 1966.

Obra própria:

Meteorologia para Aviação - Códigos e Símbolos. Em colaboração com Darcy Banci. São Paulo: Traço Editora, 1990.

\subsection{Dicionários bilíngues inglês-português especializados editados a partir de 1990}

Os dicionários desta seção são resultado de projetos pessoais capitaneados por tradutores especialistas em suas respectivas áreas de atuação. São produzidos dos anos 1990 em diante, alguns com versões eletrônicas, outros mais recentes já desenvolvidos com métodos de coleta e análise por meio de corpora eletrônicos. Inúmeros outros poderiam ter sido incluídos, mas 
novamente ressalto que procurei escolher obras representativas de um período ou tendência. Assim, os próximos tradutores lexicógrafos são símbolos de um período que coincide com o aumento do poder computacional e dos recursos eletrônicos e de uma maior especialização.

4.3.1 Marcia Buckley (1959-):Dicionário de Termos de Petróleo PortuguêsInglês. Macaé: Ed. Noble, 2001 / A Dictionary of Petroleum Terms. Macaé: Edição da autora, 2001.

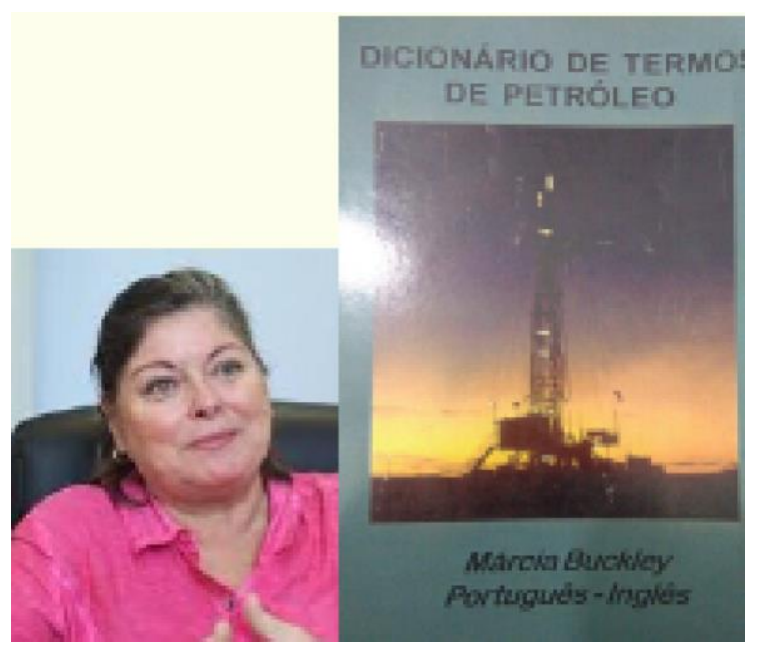

Figura 6. Foto de Marcia Buckley e capa Dicionário de Termos de Petróleo PortuguêsInglês, editado pela Noble em 2001.

Marcia Buckley é tradutora especializada desde 1975 na área de petróleo e gás e produziu seu próprio material de referência com base nos anos de experiência. É credenciada em inglês-português e português-inglês pela ABRATES - Associação Brasileira de Tradutores, membro do SINTRA - Sindicado Nacional dos Tradutores, ATA - The American Translators Association e Academia Internacional de Lexicografia.

Participou como palestrante em algumas edições dos Congressos da ABRATES, falando de forma bem-humorada das armadilhas da tradução técnica na área de petróleo. Sua obra é importante, por ser voltada especificamente para tradutores. De todos os tradutores lexicógrafos, é a única que tem um perfil mais empresarial, alinhado com o tipo de tradução especializada que realiza. Aliás, ela se apresenta como tradutora e 
empresária (Linkedin: https://www.linkedin.com/in/marcia-buckleyb2027742/?locale=pt_BR, acesso em 18 ago. 2020). Este perfil empresarial também é compartilhado por muitos colegas dessa geração, que criaram suas próprias empresas de prestação de serviços de tradução e versão de textos especializados para grandes empresas nacionais e estrangeiras. Buckley é formada em Letras pela Faculdade de Letras e Ciências de Macaé e em Administração de Empresas pela PUC-Rioe é Especialista em Tradução pelo Curso de Especialização de Tradutores Daniel Brilhante.

É proprietária da empresa Datatrans, com sede em Macaé, no Rio de Janeiro, que presta serviços de tradução desde 1987, e associada à ONIP (Organização Nacional da Indústria do Petróleo) e à Rede Petro-BC.

\subsubsection{Marcílio Moreira de Castro (1981-):Dicionário de Direito, Economia e}

Contabilidade Português-Inglês / Inglês-Português. $4^{\mathrm{a}}$ ed. Rio de Janeiro: Editora Forense, 2013. 856 p. Mais de 31 mil verbetes.

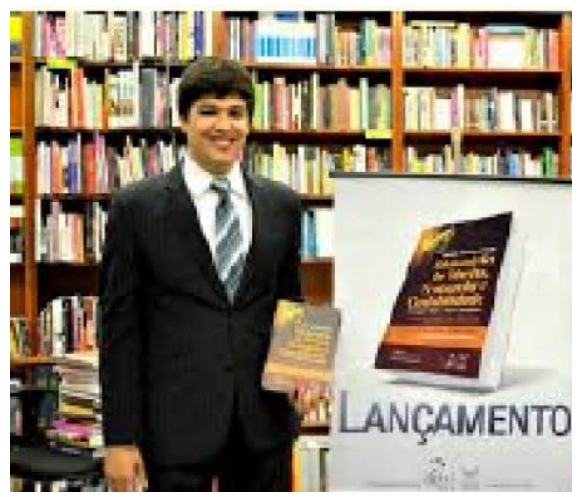

Figura 7. Marcílio Moreira de Castro, no lançamento do Dicionário de Direito, Economia e Contabilidade Português-Inglês / Inglês-Português, publicado pela Editora Forense, em 2010.

Marcílio Moreira de Castro é Juiz de Direito no Estado de São Paulo, advogado, foi tradutor juramentado no par de idiomas inglês-português, aprovado em primeiro lugar geral no concurso do Estado de Minas Gerais. Começou a traduzir (e a compilar seu dicionário) quando ingressou na Faculdade de Direito, em 1999, recebendo o incentivo de outro tradutor especializado também autor de vocabulários e glossários voltados para 
tradutores especializados, Danilo Nogueira, autor do Prefácio à edição publicada pela Forense, em 2010. Segundo Nogueira relata, a obra teve grande repercussão entre colegas tradutores, mesmo em sua edição particular, sem promoção ou comercialização profissional, por ser bastante abrangente, incluir exemplos de uso, explicações de expressões e conceitos jurídicos que muitas vezes não têm tradução direta, além de conter referências bibliográficas e alertar para a não utilização dos termos em determinados casos, informações, sem dúvida alguma, valiosas para tradutores da área jurídica. A edição pela Editora Forense é um reconhecimento do valor da obra, que tivera duas edições publicadas pelo autor em 2006 e 2008.

A edição de 2013 traz uma breve biografia do autor, ressaltando sua vasta experiência na tradução e versão de textos jurídicos, de economia e contabilidade para grandes escritórios de advocacia e multinacionais. Como obra traduzida de destaque, consta a tradução para o português, pela Editora Forense em 2011, da obra The English Legal System [O sistema jurídico inglês], de Gary Slapper \& David Kelly, com 660 páginas.

Em entrevista à Divisão de Língua Portuguesa da American Translators Association, em 2011, Marcílio conta como começou a compilar os termos que resultariam no dicionário: comparando autores de obras jurídicas nacionais estudadas durante a faculdade de Direito com autores de língua inglesa versando sobre temas correspondentes. Afirmou na época que sua intenção era continuar atualizando o dicionário, com base na experiência que adquiriu com as traduções realizadas e em mensagens que recebe de tradutores com dúvidas sobre tradução jurídica. Ele considerava "impossível terminar um dicionário". De fato, as atualizações são feitas por meio do seu blog, http://dicionariomarcilio.blogspot.com/, criado em 2008 e mantido até hoje, em que disponibiliza também aulas de tradução jurídica e análises de termos e conceitos de difícil tradução para português. Desde novembro de 2016, as edições mais atualizadas do Dicionário são disponibilizadas gratuitamente no blog em formato PDF, podendo ser consultadas on-line, baixadas e impressas pelos usuários, caso desejado. A iniciativa foi muito bem recebida pela comunidade de tradutores da área. $\mathrm{Na}$ época, o autor se dizia "realizado com o sucesso da obra" e, quando a versão 
impressa se esgotou nas livrarias, decidiu deixar de comerciá-la, considerando que as obras impressas tinham perdido utilidade.

\subsubsection{Ana Julia Perrotti-Garcia (1961-):Illustrated Dictionary of Medical and} Dental Terminology. Rio de Janeiro, Ed. Transitiva, 2016.

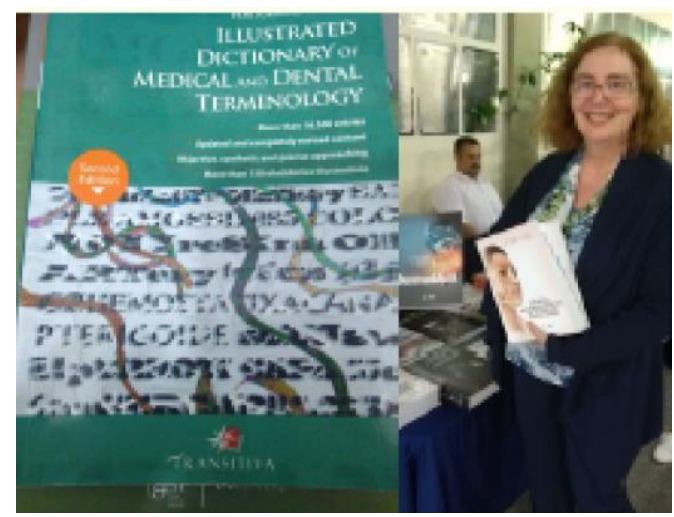

Figura 8. Capa do Illustrated Dictionary of Medical and Dental Terminology, publicado pela Ed. Transitiva, 2016 e foto de Ana Julia Perrotti-Garcia.

Ana Júlia Perrotti-Garcia é cirurgiã-dentista, tradutora, intérprete, professora e lexicógrafa, com várias obras publicadas. Começou no mundo das letras como revisora técnica de textos médicos e odontológicos traduzidos do espanhol e inglês para o português. Aos poucos, passou também a traduzir as obras e compilar termos frequentemente traduzidos equivocadamente e acabou criando o Curso de inglês odontológico e o Pequeno Dicionário Inglês-Português de Termos Odontológicos, que foram publicados nos anos 1990, pela mesma editora que a contratara para fazer as revisões (Editora Santos). Em entrevista à colega tradutora de espanhol Sonia Rodriguez Mella, publicada em seu blogTraducir Portugués (https://www.traducirportugues.com.ar),Perrotti-Garcia conta sua trajetória, afirmando ter decidido estudar tradução, depois de 10 anos de experiência como tradutora técnica: ela é Bacharel em Tradução e Interpretação pela UniFMU (Centro Universitário das Faculdades Metropolitanas Unidas, SP), especialista em Tradução (Cetrad USP), mestre em Linguística Aplicada pela PUC-SP e doutora em Inglês (FFLCH USP-SP). 
A 1a edição de seu Dicionário Ilustrado rapidamente se esgotou, e a segunda foi lançada em formato eletrônico pela Amazon. A Editora Transitiva lançou em 2017 novamente em formato impresso a 3 $3^{a}$ edição da obra, com 520 páginas.

Ao descrever seu trabalho de compilação, Perrotti-Garcia afirmou que o banco de dados de mais de 20 mil termos inglês-português compilado ainda nos anos 1990 foi usado para gerar glossários menores (publicados na Série 1001 Termos da Editora SBS), que foram enriquecidos com pesquisas em corpus, usando as ferramentas e os recursos da linguística de corpus (listas de palavras, linhas de concordância etc.).

Seu mais recente dicionário espanhol-inglês e inglês-espanhol também foi gerado com base em modernas tecnologias linguísticas, de forma a incluir os termos por critérios de relevância, com base em um corpus médico paralelo bilíngue constituído por obras científicas de oito países de língua espanhola e quatro de língua inglesa, em diferentes especialidades médicas. Está disponível em formato digital para o e-reader Kindle, da Amazon, e as versões impressas podem ser feitas sob demanda.

Tabela 4. Obras lexicográficas de Ana Julia Perrotti-Garcia

Vocabulário para odontologia. São Paulo: SBS Ed., 2003.

Vocabulário para ortodontia $\mathcal{E}$ ortopedia funcional dos maxilares. São Paulo: SBS, 2003.

Vocabulário para química: português-inglês, inglês-português. São Paulo: SBS, 2007.

Vocabulário para enfermagem. São Paulo: SBS, 2009.

Glossário de hematologia. Rio de Janeiro: Ed. Transitiva, 2016.

Grande Dicionário Ilustrado Inglês-Português de Termos Odontológicos e de Especialidades Médicas. 3ํㅡㄹ Edição. Rio de Janeiro: Ed. Transitiva, 2017.

Dictionary of Medical Terms and Expressions Spanish-English: a corpus-based bilingual vocabulary (Medical Dictionaries Book 1) (English Edition), eBook Kindle. Kindle Amazon. 


\section{Considerações finais}

Este artigo concentrou-se em dar visibilidade à participação de tradutores na produção de dicionários bilíngues, sobretudo os bilíngues especializados produzidos a partir da segunda metade do século XX no Brasil, na tentativa de reforçar a forte relação existente entre a tradução, os tradutores e a produção de dicionários. A estratégia de pesquisa baseou-se na proposta de Pym (2014), buscando traçar uma "arqueologia" dos tradutores autores dos dicionários selecionados com a intenção de mostrar que as obras são representativas de toda uma geração de tradutores e refletem o momento histórico em que se inserem.

Os exemplos apresentados comprovam que os tradutores de fato tiveram e têm participação ativa na produção dessas obras, sendo assim, agentes sociais, contribuindo de forma significativa para a melhoria da qualidade das traduções em geral e das especializadas em particular.

Confirmando o quadro mundial traçado por Boulanger (2012), as obras selecionadas e brevemente comentadas neste trabalho tiveram como autores ora tradutores lexicógrafos, ora lexicógrafos tradutores.

Os primeiros autores representam, por assim dizer, a geração em papel, antes da introdução dos computadores. Suas obras foram realizadas entre as décadas de 1940 e 1980. Em seus prefácios e apresentações, constam agradecimentos aos "datilógrafos" que ajudaram a dar forma às fichas, muito provavelmente manuscritas.

O segundo grupo revela um outro perfil. Notadamente, a partir da década de 1990, com a maior especialização técnica em inúmeras áreas, as obras passaram a ser menos abrangentes e mais específicas, concentrando-se em uma área apenas ou em áreas afins, como exemplificado pelos dicionários de petróleo, direito e contabilidade e odontologia antes descritos.

Em termos de possíveis motivações, a partir das entrevistas concedidas pelos autores mais "jovens" do grupo, pode-se inferir que seriam, entre outras, transmitir/disseminar conhecimento; contribuir para a melhoria da qualidade das traduções; alcançar projeção profissional; e deixar um legado.

Um fato observado há algum tempo, comprovado também na realização deste estudo e em conversas com colegas tradutores, é que os 
dicionários em papel praticamente já não são mais consultados. Foram aos poucos sendo substituídos por suas versões digitalizadas (em formato PDF) ou republicados em formato digital, ou acabaram ficando obsoletos por não refletirem os avanços da produção científica recente.

Para o futuro, creio que ainda veremos bons frutos dos novos trabalhos realizados com corpora eletrônicos. Projetos para criação de dicionários bilíngues atuais já contam com novas tecnologias integradas com softwares específicos de análise de grandes volumes de textos, incluindo análises de frequência, identificação de colocações usadas com certos termos/palavras, identificação de fraseologias específicas, geração de listas de palavras, listas de concordâncias. Enfim, um mundo de possibilidades fascinantes que certamente atrairão tradutores em suas equipes. Questionamentos permanecem, claro. Será que de fato os dicionários ainda serão necessários diante da onipresença e disponibilidade praticamente instantânea na web de bilhões de palavras em dezenas de idiomas? Será que os lexicógrafos continuarão a ser necessários, para compilar toda essa informação em dicionários? Será que os dicionários existentes realmente atendem às necessidades dos usuários? Que usuários são esses? Como saber se os produtos gerados são realmente eficazes? Será que os tradutores continuarão a participar desses projetos, criando seus próprios dicionários bilíngues, conforme a especialização? Que consequências essa tendência pode trazer?

Acredito que o mundo da lexicografia em geral e da lexicografia bilíngue em particular continuará se adaptando aos avanços tecnológicos para fazer bom uso dos recursos disponíveis. Para isso, certamente contará com a relevante participação de tradutores em seus projetos.

\section{Referências}

ATKINS, S.; RUNDELL, M. The Oxford Guide to Practical Lexicography. New York: Oxford University Press, 2008.

BIDERMAN, M; T. C. A ciência da lexicografia. Alfa, v. 28 (Supl.), p. 1-26, 1984. 
BIDERMAN, M; T. C. A formação e a consolidação da norma lexical e lexicográfica no português do Brasil. In: NUNES, J. H.; PETTER, M. (org.) História do saber lexical e constituição de um léxico brasileiro. São Paulo: Humanitas/FFLCH/USP: Pontes, 2002, p. 65-82.

BOTTMAN, D. Leonel Vallandro Tradutor. Não gosto de plágio: um blog contra plágios de tradução e variedades várias. Disponível em: http://naogostodeplagio.blogspot.com/2018/07/leonel-vallandrotradutor.html. Acesso em: 22 jun. 2020.

CASTRO, M. M. de. Lançamento do Dicionário Marcílio Moreira de Castro: entrevista. [10 de outubro de 2011] ATA PLD. Entrevista concedida a Naomi Sutcliffe de Moraes. Disponível em: https://www.atadivisions.org/PLD/index.php/2011/10/10/entrevista-com-marcilio-moreirade-castro/. Acesso em: 18 jun. 2020.

CUNHA, M. B. da. Manual de fontes de informação. $2^{\underline{a}}$ ed. Brasília: Briquet de Lemos / Livros, 2020.

D'HULST, L. Why and How to Write Translation Histories? Crop 6 (Tema: Emerging Views in Translation History in Brazil), p. 21-32, 2001.

D'HULST, L. Translation History. In: GAMBIER, Yves; VAN DOORSLAER, Luc (org.). Handbook of Translation Studies, Volume 1. Amsterdam: John Benjamins, 2010, p. 398-405.

DO CARMO, L.; VILLALVA, A.; CARDEIRA, E. Words denoting 'hill' in Portuguese and Brazilian dictionaries. In: VILLALVA, A.; WILLIAMS, G. (org.) The Landscape of Lexicography. Porto: Centro de Linguística da Universidade de Lisboa/Centro de Línguas, Literaturas e Culturas da Universidade de Aveiro, 2019.

BOULANGER, J. C. Translators and the production of dictionaries. In: DELISLE, J.; WOODSWORTH, J. (Eds.), Translators through History. Amsterdam/Philadelphia: John Benjamins, 2012, p. 223-246.

GRANGER, S.; PAQUOT, M. Electronic Lexicography. Oxford: Oxford University Press, 2012.

GUEDES, P. V.; RIBEIRO, B. T. Contribuições e problemas na elaboração de um dicionário bilíngue inglês/português. In: IV Congresso Nacional de Linguística e Filologia em Homenagem a Antônio Houaiss, 2000. Anais do 
CNLF. Disponível em: http://www.filologia.org.br/cong_ivcnlf10.html. Acesso em: 19 jun. 2020.

HALLEWELL, L. O livro no Brasil: sua história. São Paulo: T.A. Queiroz; Editora da Universidade de São Paulo (EDUSP), 1985.

HANES, V. L. L; GUERINI, A. Leonel Vallandro. Verbete do Dicionário de Tradutores Literários no Brasil (DITRA). Florianópolis: NUPLITT - Núcleo de Pesquisas em Literatura e Tradução, UFSC, 2013. Disponível em http://www.dicionariodetradutores.ufsc.br/pt/LeonelVallandro.htm. Acesso em: 22 jun. 2020.

ITAÚ CULTURAL: ANTÔNIO Houaiss. In: ENCICLOPÉDIA Itaú Cultural de Arte e Cultura Brasileiras. São Paulo: Itaú Cultural, 2020. Disponível em: http://enciclopedia.itaucultural.org.br/pessoa14496/antonio-houaiss. Acesso em: 16 jun. 2020. Verbete da Enciclopédia. ISBN: 978-85-7979-060-7.

JACKSON, K. D. Literatura, cultura \& civilização: estudos do Brasil nos Estados Unidos: levantamento histórico e avaliação. In: BARBOSA, R. A.; EAKIN, M. C.; ALMEIDA, P. R. de. (org.) O Brasil dos brasilianistas: um guia de estudos sobre o Brasil nos Estados Unidos, 1945-2000. São Paulo: Paz e Terra, 2002, p. 114-149.

KRIEGER, M. G.; MÜLLER, A. F., GARCIA, A. R. R.; BATISTA, R. P. O século $\mathrm{XX}$, cenário dos dicionários fundadores da lexicografia brasileira: relações com a identidade do português do Brasil. Alfa, v. 50, n. 2, p. 173187, 2006.

LABANCA, G. C. Publicações Pan-Americanas e Editora Gertum Carneiro: dos livros técnicos às edições de bolso. In: II Seminário Brasileiro Livro e História Editorial, 2009. Anais eletrônicos. Rio de Janeiro. Disponível em: http://www.livroehistoriaeditorial.pro.br/ii_pdf/Gabriel_Costa_Labanca.pd f. Acesso em: 15 jun. 2020.

NUNES, J. H. A dicionarização no Brasil. In: NUNES, J. H.; PETTER, M. (org.) História do saber lexical e constituição de um léxico brasileiro. São Paulo: Humanitas/FFLCH/USP: Pontes, 2002, p. 99-120.

OLIVEIRA HARDEN, A. R. de. Brasileiro tradutor e/ou traidor: frei José Mariano da Conceição Veloso. Cadernos de Tradução, v. 1, n. 23, p. 131-148, 2009. 
PACHECO, L. P. B. Os pesquisadores do Brasil e o imperialismo no pósguerra: o campo da historiografia do Departamento de Estado. In: VIII Encontro Estadual de História da Anpuh-BA, 2016. Anais eletrônicos. Feira de Santana.Disponível em: http://www.encontro2016.bahia.anpuh.org/ site/anaiscomplementares\#L. Acesso em: 18 jun. 2020.

PERROTTI-GARCIA, A. J. Entrevista com a Dra. Ana Júlia Perrotti-Garcia. [13 de julho de 2017] Traducir Portugués. Entrevista concedida a Sonia Rodríguez Mella. Disponível em: https:/www.traducirportugues.com.ar/ 2017/07/Ana-Julia-Perrotti-Garcia-Entrevista.html. Acesso em: 22 jun. 2020.

PINILLA, J. A. S. A história da tradução do Brasil: questões de pesquisa. In: Tradução em Revista n.28, p. 13-31, 2020.1. Disponível em https://www.maxwell.vrac.puc-

rio.br/rev_trad.php?strSecao $=$ fasciculo $\&$ fas $=48452 \& N r S e c a o=11$. Acesso em: 22 jun. 2020.

PYM, A. Method in Translation History. Nova York: Routledge, 2014. Publicado originalmente pela John Benjamins, 1998.

SILVA, C. P. A da. Cantinho de Histórias: Meu irmão Meteorologista Tradutor. BIP - Boletim dos Inativos e Pensionistas da Aeronáutica, n. 58, 2007. Disponível em: https://www.redemet.aer.mil.br/uploads/2014/04/ Meu_irmao_met.pdf. Acesso em: 15 jun. 2020.

SILVA-REIS, D. Por uma história da tradução técnico-científica no Brasil do século XVI ao XIX. In: ALVES, D. A. S; BRANCO, S.O. (org.). Discussões contemporâneas sobre os Estudos da Tradução: reflexões e desenvolvimentos a partir do IV Encontro Nacional Cultura e Tradução. Campinas, SP: Pontes, 2019, p. 15-34.

TOOGE, M. Nas páginas dos jornais: o caráter diplomático atribuído à tradução literária em meados do século XX. Tradterm, n. 15, p. 59-78, 2009. Disponível em: https://doi.org/10.11606/issn.2317-9511.tradterm.2009.46336. Acesso em: 20 jun. 2020.

VERDELHO, T. Dicionários portugueses. In: NUNES, J. H.; PETTER, M. (org.) História do saber lexical e constituição de um léxico brasileiro. São Paulo: Humanitas/FFLCH/USP: Pontes, 2002, p. 15-64.

VERDELHO, T. Os dicionários bilíngues até o fim do séc. XVIII, Fonte privilegiada da lexicografia portuguesa. Colóquio de lexicologia e 
lexicografia (26 a 27 de junho de 1990). Actas, Lisboa, INIC. Univ. Nova de Lisboa, 1991, p. 248-56.

VERDELHO, T.; SILVESTRE, J. P. (org.) Lexicografia Bilíngue: A tradição dicionarística Português-Línguas Modernas. Lisboa: Centro de Linguística da Universidade de Lisboa, 2011.

WYLER, L. Línguas, poetas e bacharéis: uma crônica da tradução no Brasil. Rio de Janeiro: Rocco, 2003.

\title{
Resumo
}

O presente artigo investiga o papel da tradução e dos tradutores na produção de dicionários bilíngues especializados, com ênfase no par de idiomas inglêsportuguês, a partir da segunda metade do século XX no Brasil. O objetivo é dar visibilidade aos tradutores autores dos dicionários selecionados para o estudo, por meio de uma visão histórica, com base em Pym (2014), chegando aos dias atuais, na tentativa de entender qual será a participação da tradução e dos tradutores nesse processo no futuro.

Palavras-chave: História da tradução; Dicionários bilíngues; Tradução especializada

\begin{abstract}
This paper investigates the role of translation and translators in the production of specialized bilingual dictionaries, focusing on the EnglishPortuguese language pair, as of the second half of the 20th century in Brazil. The objective is to give visibility to the translators who wrote the dictionaries selected for the study, through a historical perspective, based on Pym (2014), up to the present day in an attempt to understand how translation and translators will participate in this process in the future.
\end{abstract}

Keywords: Translation history; Bilingual dictionaries; Specialized translation 